\title{
Genotypic and Phenotypic Assessment of Hyaluronidase among Type Strains of a Select Group of Staphylococcal Species
}

\author{
Mark E. Hart, ${ }^{1,2}$ Morgan J. Hart, ${ }^{3}$ and Anna J. Roop ${ }^{3}$ \\ ${ }^{1}$ Division of Microbiology, National Center for Toxicological Research, U.S. Food and Drug Administration, Jefferson, \\ AR 72079, USA \\ ${ }^{2}$ Department of Microbiology and Immunology, University of Arkansas for Medical Sciences, Little Rock, AR 72205, USA \\ ${ }^{3}$ Department of Biology, Ouachita Baptist University, Arkadelphia, AR 71998, USA \\ Correspondence should be addressed to Mark E. Hart, mark.hart@fda.hhs.gov
}

Received 13 August 2009; Accepted 15 October 2009

Recommended by William M. Shafer

\begin{abstract}
Hyaluronidases degrade hyaluronic acid, a major polysaccharide of the extracellular matrix of tissues, and are considered important for virulence in a number of Gram-positive and -negative bacteria. The purpose of the present study was to determine the prevalence of hyaluronidase among clinical strains of Staphylococcus aureus and among other Staphylococcus species. Spent media and chromosomal DNA were assessed for hyaluronidase activity and the absence or presence of a hyaluronidase gene (hysA) by Southern analysis, respectively. All S. aureus strains examined exhibited at least one hybridizing band (half of the strains exhibited two or more hybridizing bands) when probed for hys $A$ and all but three of these strains produced hyaluronidase. In contrast, none of the type strains of 19 other species exhibited either hyaluronidase activity or hybridizing bands when probed for hysA. These data support the hypothesis that among members of the Staphylococcus genus only strains of S. aureus possess the enzyme hyaluronidase. This would suggest that hyaluronidase represents yet another potential virulence factor employed by $S$. aureus to cause disease and may represent a diagnostically important characteristic for distinguishing $S$. aureus from other members of this genus.
\end{abstract}

Copyright () 2009 Mark E. Hart et al. This is an open access article distributed under the Creative Commons Attribution License, which permits unrestricted use, distribution, and reproduction in any medium, provided the original work is properly cited.

\section{Introduction}

Hyaluronidase, an enzyme that primarily degrades hyaluronic acid, a major component of the extracellular matrix of human tissues, has been found in both Gram-positive and -negative bacteria and, in several cases, has been implicated in the disease process as a means to either invade tissues or generate a source of carbon and energy [1-8]. A role for hyaluronidase in $S$. aureus diseases has been suggested by Makris et al. [9], who demonstrated, using a mouse abscess model, that the number of viable cells recovered for a hyaluronidase mutant strain was significantly less than that for its parent strain. Recent proteomic studies of spent media from Staphylococcus aureus UAMS-1 and its regulatory mutants, sarA, agr, and sarA agr, detected two different proteins identified as hyaluronidases [10]. Concentrations of these proteins were higher in the sarA and sarA agr mutant strains than in the parent and agr mutant strains, suggesting the involvement of SarA, an important regulator of virulence in S. aureus, in the regulation of hyaluronidase [10]. While the exact role of hyaluronidase in S. aureus is not known, the involvement of sarA in the regulation of the hyaluronidase gene $(h y s A)$ expression $[9,10]$ and the identification of genes annotated as putative hyaluronidases in all fourteen sequenced strains of $S$. aureus [11] would indicate that $S$. aureus hyaluronidase is a virulence factor important for some aspect of disease.

The genus Staphylococcus is a diverse group of some 41 known species $[12,13]$. In the human clinical setting the production of coagulase is usually used to distinguish between $S$. aureus and all other species, which are typically grouped together as the coagulase-negative staphylococci (CoNS) [14]. However, species other than S. aureus produce coagulase even though their encounter in the human clinical 
setting is rare [14-18]. These species are S. intermedius, $S$. delphini, S. schleiferi subsp. coagulans, S. hyicus subsp. hyicus, and S. lutrae [13, 19-22].

The presence or absence of hyaluronidase among the staphylococci has been examined, previously. For example, Choudhuri and Chakrabarty [23] examined 523 staphylococcal isolates from human pathologies, and of the $96 \%$ that were coagulase positive, only $13 \%$ were negative for hyaluronidase activity. Nine of the remaining 21 strains that were coagulase-negative were shown not to produce hyaluronidase [23]. Essers and Radebold [24] examined 368 staphylococcal strains isolated from human specimens, and of the 218 determined to be coagulase positive, only one isolate was hyaluronidase negative. Of the remaining 150 strains determined to be coagulase negative, only one isolate had hyaluronidase activity [24]. An additional 495 strains were examined for their ability to produce DNAse and hyaluronidase [24]. Only ten of the 323 DNAse positive strains were negative for hyaluronidase activity while 170 of the remaining 172 strains designated DNAse negative were also negative for hyaluronidase activity. Collectively, these data $[23,24]$ indicate that hyaluronidase activity is predominantly seen among strains of staphylococci that exhibit both coagulase and DNAse activity, two characteristics typically used to distinguish $S$. aureus from other staphylococcal species, at least in the context of human disease [13]. While it appears that hyaluronidase activity is found among nearly all strains of $S$. aureus, S. hyicus subsp. hyicus, a strain known to cause infectious exudative epidermititis in swine, has also been reported positive for hyaluronidase activity $[13,19,25]$. To the best of our knowledge, hyaluronidase activity among other species of Staphylococcus has not been systematically examined. The purpose of the present study was to determine the prevalence of hyaluronidase in members of the genus Staphylococcus, primarily those associated with human disease.

\section{Materials and Methods}

2.1. Staphylococcal Strains and Growth Conditions. S. aureus strains used in this study are listed in Table 1. While these strains were obtained primarily from two sources, the University of Arkansas for Medical Sciences and the University of Nebraska Medical Center, the strains represent a diverse group of clinical isolates originally obtained from different geographical locations, outbreaks, and disease syndromes. Other species examined were $S$. auricularis ATCC $33753^{\mathrm{T}}$, S. capitis subsp. capitis ATCC $27840^{\mathrm{T}}$, S. caprae ATCC $35538^{\mathrm{T}}$, S. carnosus subsp. carnosus ATCC $51365^{\mathrm{T}}$, S. chromogenes ATCC $43764^{\mathrm{T}}$, S. cohnii subsp. cohnii ATCC 29974 ${ }^{\mathrm{T}}$, S. delphini ATCC $49171^{\mathrm{T}}$, S. epidermidis ATCC $14990^{\mathrm{T}}$, S. epidermidis ATCC 12228, S. haemolyticus ATCC $29970^{\mathrm{T}}$, S. hominis subsp. hominis ATCC $27844^{\mathrm{T}}$, S. hyicus subsp. hyicus ATCC $11249^{\mathrm{T}}$, S. intermedius ATCC $29663^{\mathrm{T}}$, S. lugdunensis ATCC $43809^{\mathrm{T}}$, S. saprophyticus ATCC $19701^{\mathrm{T}}$, S. schleiferi subsp. coagulans ATCC $49549^{\mathrm{T}}$, S. schleiferi subsp. schleiferi ATCC $43808^{\mathrm{T}}$, S. sciuri subsp. sciuri ATCC $29062^{\mathrm{T}}$, S. simulans ATCC $27848^{\mathrm{T}}$, S. warneri ATCC $27836^{\mathrm{T}}$, and S. xylosus ATCC $29971^{\mathrm{T}}$. Strains were maintained as frozen $\left(-80^{\circ} \mathrm{C}\right)$ stocks in brain heart infusion broth (BHI; Difco Laboratories, Detroit, Mich.) containing 25\% (w/v) glycerol and routinely streaked for isolation on tryptic soy broth (TSB; Difco) containing agar (1.5\%). Flasks containing $20 \mathrm{~mL}$ of TSB were inoculated from plate cultures and incubated at $37^{\circ} \mathrm{C}$ overnight (15-18 hours) with rotary (180 rpm) aeration.

2.2. DNA Isolation and Southern Analysis. Chromosomal DNA was isolated using the GenElute Bacterial Genomic DNA Kit (Sigma-Aldrich Chemical Co., St. Louis, Mo) and digested with ClaI restriction endonuclease, resolved by agarose gel electrophoresis, and transferred to neutral nylon membranes (MagnaGraph; Micron Separations Inc., Westborough, Mass.) by passive diffusion. Membranes were hybridized overnight with a digoxigenin-labeled (Roche Molecular Biochemicals, Indianapolis, Ind.) amplicon generated by PCR using either S. aureus UAMS-1 or RN6390 (8325 lineage) chromosomal DNA as template and primers (5'-GTGGATTGTTTGACAGTAGACAG-3' and 5' CGGTATTTGTAGATTCGGGATTATAG-3') designed from the known genomic sequence of S. aureus N315 [26]. The amplicons were cloned and their identities were verified by sequencing. Each amplicon (probe) was $2,442 \mathrm{bp}$ in size beginning 116 bases upstream of the start codon and ending approximately 100 bases short of the end of the gene.

Hybridization was carried out at $65^{\circ} \mathrm{C}$ and hybridizing bands were detected by autoradiography using alkaline phosphatase-conjugated antidigoxigenin $\mathrm{F}\left(\mathrm{ab}^{\prime}\right)_{2}$ antibody fragments (Roche Molecular Biochemicals) and the chemiluminescent substrate CDP-Star (Roche Molecular Biochemicals).

2.3. Concentration of Spent Media. Optical density readings of overnight cultures (15-18 hours) were determined spectrophotometrically at $550 \mathrm{~nm}$ and used to dilute each culture with TSB to an optical density of 3.0 in a total volume of $10 \mathrm{~mL}$. Diluted cultures were centrifuged $(10,000 \times g$, for 10 minutes at $4^{\circ} \mathrm{C}$ ) and spent media were filter sterilized before concentration using ultrafiltration (Centricon Ultracel YM3 filters with 3,000 MWCO, Millipore Corporation, Bedford, Maine) and a one-hour centrifugation $(7,500 \times g)$ at $4^{\circ} \mathrm{C}$. The retentates were recovered and stored at $-80^{\circ} \mathrm{C}$ until needed.

\subsection{Plate Assay for Detecting Hyaluronidase in Spent Media.} Sterile plastic square plates containing $1 \%(\mathrm{w} / \mathrm{v})$ SeaKem LE agarose (Cambrex BioScience Rockland, Inc., Rockland, Maine), 1\% (w/v) bovine serum albumin (BSA; Fraction V; Fisher Scientific, Fair Lawn, NJ), and $0.4 \mathrm{mg} \mathrm{mL}^{-1}$ of hyaluronic acid (HA; Sigma, H-1504; potassium salt, from human umbilical cord) in $0.3 \mathrm{M}$ sodium phosphate buffer ( $\mathrm{pH}$ 5.3) were prepared according to Steiner and Cruce [27]. Once the agarose medium containing BSA and HA had solidified, $4 \mathrm{~mm}$ wells were made aseptically, and $20 \mu \mathrm{L}$ of spent media was pipetted into each well. Plates were incubated overnight (15-18 hours) at $37^{\circ} \mathrm{C}$ prior to flooding each plate with $2 \mathrm{M}$ acetic acid. Clear zones were visualized against 
TABLE 1: Hyaluronidase activity of Staphylococcus aureus strains.

\begin{tabular}{|c|c|c|c|c|}
\hline Strain & Relevant description & Source & HA activity* & hys $A^{\#}$ \\
\hline $\mathrm{NCH} 265$ & ATCC 29213 & ATCC $^{\S}$ & $13.2 \pm 1.3$ & 1 \\
\hline NCH 340 & ATCC $12600^{\mathrm{T}}$ & ATCC & $9.7 \pm 0.6$ & 1 \\
\hline NTH 125 & ATCC 25923 & ATCC & $8.7 \pm 0.8$ & 2 \\
\hline $\mathrm{NCH} 49$ & MN8 (vaginal TSS ${ }^{\natural}$ ) & $\mathrm{NARSA}^{\dagger}$ & $8.7 \pm 0.3$ & 2 \\
\hline $\mathrm{NCH} 47$ & Mu50 (HA-MRSA) & NARSA & $9.2 \pm 0.3$ & 1 \\
\hline NCH 51 & MW2 (CA-MRSA) & NARSA & $9.5 \pm 0.5$ & 1 \\
\hline $\mathrm{NCH} 48$ & N315 (HA-MRSA) & NARSA & $7.0 \pm 0.5$ & 1 \\
\hline NCH 328 & Newman & T. Foster, Trinity College, Dublin, Ireland & $5.8 \pm 2.5$ & 1 \\
\hline $\mathrm{NCH} 331$ & Newman $(\operatorname{sig} B)$ & T. Foster, Trinity College, Dublin, Ireland & $10.0 \pm 0$ & 1 \\
\hline $\mathrm{NCH} 88$ & Sanger-252 (EMRSA-16) & NARSA & $7.2 \pm 2.0$ & 2 \\
\hline NCH 78 & SH1000 (RN6390, $\left.r s b^{+}\right)$ & S. Foster, Univ. Sheffield, Sheffield, England & $11.3 \pm 0.6$ & 1 \\
\hline $\mathrm{NCH} 79$ & SH1000 (RN6390, rsb) & S. Foster, Univ. Sheffield, Sheffield, England & $12.5 \pm 3.0$ & 1 \\
\hline NTH 13 & UAMS-1 & M.S. Smeltzer, UAMS' & $9.0 \pm 1.3$ & 2 \\
\hline $\mathrm{NCH} 310$ & USA300 (Miss.) & M.S. Smeltzer, UAMS & $9.8 \pm 0.3$ & 1 \\
\hline NCH 338 & USA300 (LAC) & A.R. Horswill, University of Iowa & $10.2 \pm 1.6$ & 1 \\
\hline $\mathrm{NCH} 239$ & Vaginal TSS & P.D. Fey, UNMC! & $6.8 \pm 0.6$ & 2 \\
\hline $\mathrm{NCH} 240$ & Vaginal TSS & P.D. Fey, UNMC & $8.8 \pm 1.8$ & 1 \\
\hline $\mathrm{NCH} 241$ & Vaginal TSS & P.D. Fey, UNMC & $0 \pm 0$ & 2 \\
\hline $\mathrm{NCH} 242$ & Vaginal TSS & P.D. Fey, UNMC & $0 \pm 0$ & 1 \\
\hline NCH 243 & Vaginal TSS & P.D. Fey, UNMC & $8.5 \pm 0.7$ & 2 \\
\hline $\mathrm{NCH} 244$ & Vaginal TSS & P.D. Fey, UNMC & $10.0 \pm 0.5$ & 1 \\
\hline NCH 245 & Vaginal TSS & P.D. Fey, UNMC & $9.7 \pm 0.6$ & 2 \\
\hline NCH 246 & Vaginal TSS & P.D. Fey, UNMC & $7.8 \pm 0.8$ & 2 \\
\hline NCH 247 & Vaginal TSS & P.D. Fey, UNMC & $6.7 \pm 1.2$ & 1 \\
\hline NCH 248 & Vaginal TSS & P.D. Fey, UNMC & $8.0 \pm 1.7$ & 2 \\
\hline NCH 249 & Vaginal TSS & P.D. Fey, UNMC & $8.0 \pm 0.9$ & 2 \\
\hline $\mathrm{NCH} 250$ & Vaginal TSS & P.D. Fey, UNMC & $0 \pm 0$ & 2 \\
\hline $\mathrm{NCH} 251$ & Vaginal TSS & P.D. Fey, UNMC & $8.3 \pm 1.0$ & 2 \\
\hline $\mathrm{NCH} 252$ & Vaginal TSS & P.D. Fey, UNMC & $7.3 \pm 0.8$ & 2 \\
\hline $\mathrm{NCH} 253$ & Vaginal TSS & P.D. Fey, UNMC & $6.8 \pm 1.0$ & 2 \\
\hline NCH 254 & Vaginal TSS & P.D. Fey, UNMC & $8.2 \pm 0.8$ & 2 \\
\hline NTH 68 & UAMS-625 (Abscess) & M.S. Smeltzer, UAMS & $11.0 \pm 3.0$ & 1 \\
\hline NTH 69 & UAMS-632 (Wound) & M.S. Smeltzer, UAMS & $6.2 \pm 1.0$ & 2 \\
\hline NTH 70 & UAMS-635 (Blood) & M.S. Smeltzer, UAMS & $13.5 \pm 1.3$ & 1 \\
\hline NTH 71 & UAMS-636 (Wound) & M.S. Smeltzer, UAMS & $13.0 \pm 0$ & 1 \\
\hline NTH 72 & UAMS-639 (Tracheal) & M.S. Smeltzer, UAMS & $8.7 \pm 0.8$ & 2 \\
\hline NTH 73 & UAMS-640 (Abscess) & M.S. Smeltzer, UAMS & $10.3 \pm 0.6$ & 2 \\
\hline NTH 74 & UAMS-641 (Blood) & M.S. Smeltzer, UAMS & $7.2 \pm 1.0$ & 2 \\
\hline NTH 75 & UAMS-655 (Blood) & M.S. Smeltzer, UAMS & $13.2 \pm 0.8$ & 2 \\
\hline NTH 76 & UAMS-682 (Outbreak 2) & M.S. Smeltzer, UAMS & $12.0 \pm 1.0$ & 2 \\
\hline NTH 77 & UAMS-687 & M.S. Smeltzer, UAMS & $9.0 \pm 0.5$ & 1 \\
\hline NTH 78 & UAMS-688 & M.S. Smeltzer, UAMS & $11.8 \pm 0.8$ & 2 \\
\hline NTH 79 & UAMS-689 & M.S. Smeltzer, UAMS & $10.8 \pm 0.8$ & 3 \\
\hline NTH 80 & UAMS-690 (Outbreak 1) & M.S. Smeltzer, UAMS & $0.5 \pm 0.6$ & 1 \\
\hline NTH 81 & UAMS-691 (Outbreak 2) & M.S. Smeltzer, UAMS & $12.8 \pm 1.0$ & 3 \\
\hline NTH 82 & UAMS-697 & M.S. Smeltzer, UAMS & $14.0 \pm 0.5$ & 1 \\
\hline
\end{tabular}

*Values represent the mean diameter in millimeters \pm the standard deviation of three independent determinations.

\#Values represent the number of chemiluminescent bands detected when hybridized with a hysA specific probe.

$\S$ American Type Culture Collection (ATCC), Manassas, Va.

${ }^{\mathrm{T}}$ Type strain

"Toxic shock syndrome.

${ }^{\dagger}$ Network for Antimicrobial Resistant Staphylococcus aureus.

University of Arkansas for Medical Sciences, Little Rock, Ark.

! University of Nebraska Medical Center, Omaha, Neb. 


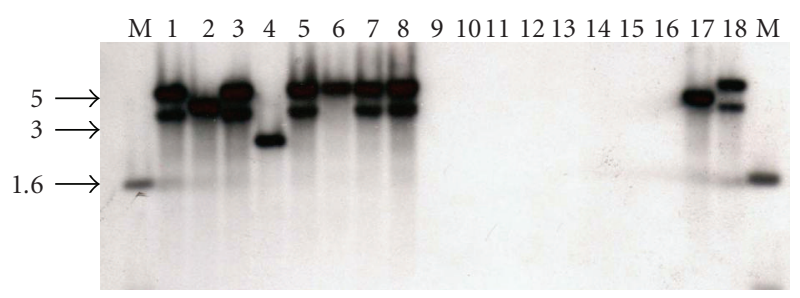

(a)

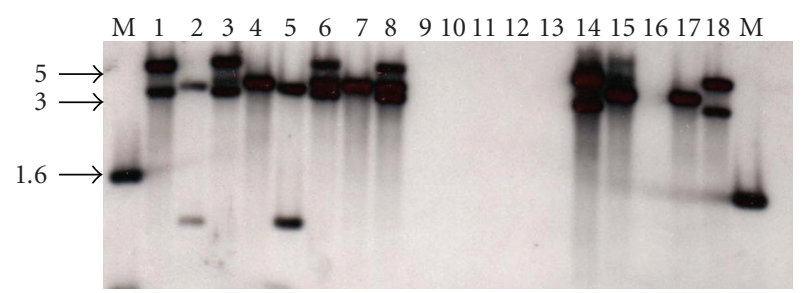

(b)

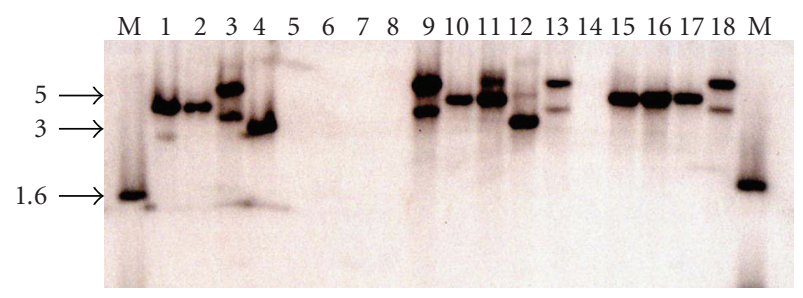

(c)

Figure 1: Southern analysis of chromosomal DNA from Staphylococcus species hybridized with a probe specific for hysA. Panel (a) S. aureus NCH 239 (1), NCH 240 (2), NCH 241 (3), NCH 242 (4), NCH 243 (5), NCH 244 (6), NCH 245 (7), NCH 246 (8), S. auricularis ATCC $33753^{\mathrm{T}}$ (9), S. capitis subsp. capitis ATCC $27840^{\mathrm{T}}$ (10), S. caprae ATCC $35538^{\mathrm{T}}$ (11), S. carnosus subsp. carnosus ATCC $51365^{\mathrm{T}}$ (12), S. chromogenes ATCC $43764^{\mathrm{T}}$ (13), S. cohnii subsp. cohnii ATCC $29974^{\mathrm{T}}$ (14), S. delphini ATCC $49171^{\mathrm{T}}$ (15), S. hominis subsp. hominis ATCC $27844^{\mathrm{T}}$ (16), S. aureus $\mathrm{NCH} 78$ (17), and NCH 88 (18). Panel (b) S. aureus NTH 74 (1), NTH 75 (2), NTH 76 (3), NTH 77 (4), NTH 78 (5), NTH 79 (6), NTH 80 (7), NTH 81 (8), S. intermedius ATCC $29663^{\mathrm{T}}$ (9), S. lugdunensis ATCC $43809^{\mathrm{T}}$ (10), S. saprophyticus ATCC $19701^{\mathrm{T}}$ (11), S. schleiferi subsp. schleiferi ATCC $43808^{\mathrm{T}}$ (12), S. epidermidis ATCC 12228 (13), S. aureus NTH 125 (14), NCH 265 (15), S. intermedius ATCC 29633' (16), NCH 78 (17), and NCH 88 (18). Panel (c) S. aureus NCH 47 (1), NCH 48 (2), NCH 49 (3), NCH 51 (4), S. sciuri subsp. sciuri ATCC 29062 (5), S. simulans ATCC $27848^{\mathrm{T}}$ (6), S. warneri ATCC $27836^{\mathrm{T}}$ (7), S. xylosus ATCC $29971^{\mathrm{T}}(8)$, S. aureus NTH 13 (9), NCH 78 (10), NCH 79 (11), NTH 82 (12), NCH 88 (13), S. haemolyticus ATCC $29970^{\mathrm{T}}$ (14), NCH 328 (15), NCH 331 (16), NCH 78 (17), and NCH 88 (18). M: marker (kilobases).

a background of opaque precipitated BSA conjugated to undigested HA and their diameters measured in millimeters. Purified bovine testicular hyaluronidase (Sigma, H-3506) was used as a positive control.

2.5. Plate Assay for Detecting Hyaluronidase-Producing Colonies in Mixed Culture. Tryptic soy broth $(6 \mathrm{~g}$ in $120 \mathrm{~mL}$ of water) containing $1 \%(\mathrm{w} / \mathrm{v})$ agarose was sterilized by autoclaving. The molten medium was equilibrated to $50^{\circ} \mathrm{C}$

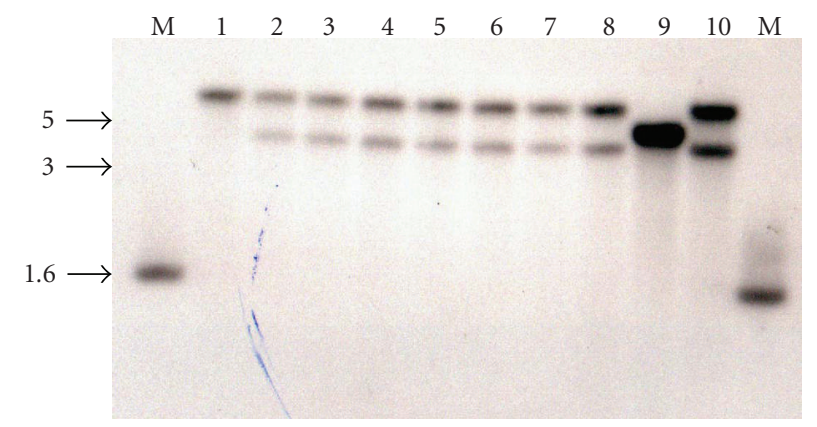

(a)

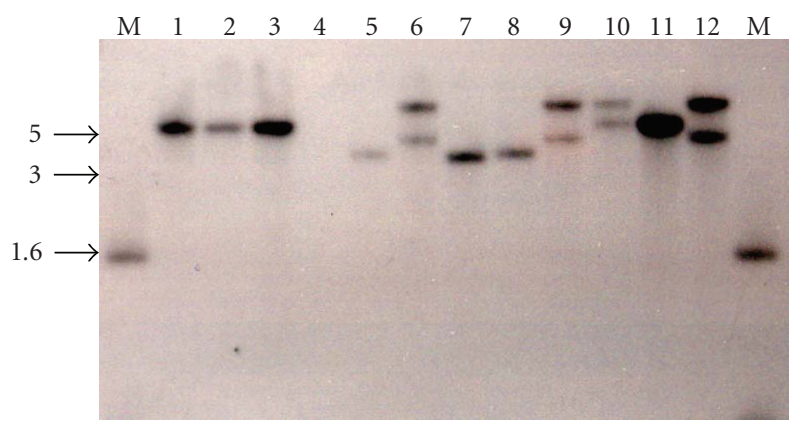

(b)

FIGURE 2: Southern analysis of chromosomal DNA from Staphylococcus species hybridized with a probe specific for hysA. Panel (a) S. aureus NCH 247 (1), NCH 248 (2), NCH 249 (3), NCH 250 (4), $\mathrm{NCH} 251$ (5), NCH 252 (6), NCH 253 (7), NCH 254 (8), NCH 78 (9), and NCH 88 (10). Panel (b) S. aureus NCH 310 (1), NCH 338 (2), NCH 340 (3), S. epidermidis ATCC $14990^{\mathrm{T}}$ (4), S. aureus NTH 68 (5), NTH 69 (6), NTH 70 (7), NTH 71 (8), NTH 72 (9), NTH 73 (10), NCH 78 (11), and NCH 88 (12). M: marker (kilobases).

prior to the addition of $40 \mathrm{~mL}$ of filter-sterilized BSA (5\% $[\mathrm{w} / \mathrm{v}]$ prepared in water) and $40 \mathrm{~mL}$ of filter-sterilized HA $\left(1 \mathrm{mg} \mathrm{mL}{ }^{-1}\right.$ prepared in water) both equilibrated to $50^{\circ} \mathrm{C}$. The suspension was mixed and dispensed as $20 \mathrm{~mL}$ portions into each of ten Petri plates $(15 \times 100 \mathrm{~mm})$. The medium (TSHA) was allowed to solidify and plates were incubated overnight at $37^{\circ} \mathrm{C}$ before use. Overnight cultures of $S$. aureus strains ATCC 33753 and Newman and S. epidermidis strain ATCC 12228 were diluted with TSB, mixed in equal portions, and plated onto TSHA plates to yield 30-300 colonies per plate. Plates were incubated overnight (15-18 hours) at $37^{\circ} \mathrm{C}$ prior to flooding each plate with $2 \mathrm{M}$ acetic acid to precipitate undigested HA conjugated to BSA.

\section{Results}

3.1. Hyaluronidase Activity of S. Aureus. Hyaluronidase activity was detected for 93\% (40 of 43) of S. aureus strains (Table 1) examined while none of the remaining species exhibited hyaluronidase activity (data not shown) including S. hyicus subsp. hyicus ATCC $11249^{\mathrm{T}}$ (Figure 3(a)); the only species other than $S$. aureus reported to have hyaluronidase activity $[13,19,25]$. 


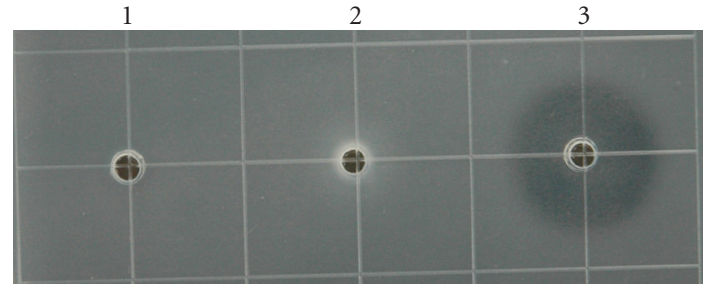

(a)

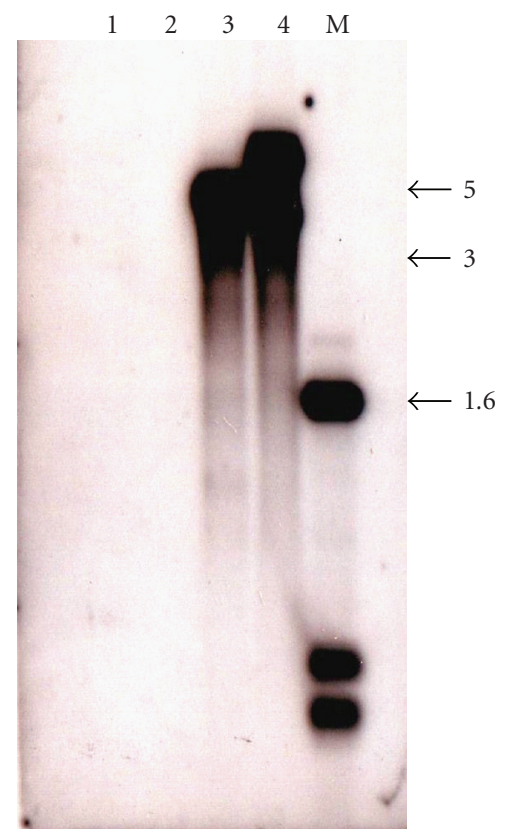

(b)

Figure 3: Panel (a) Hyaluronidase activity from spent media isolated from S. hyicus subsp. hyicus ATCC $11249^{\mathrm{T}}$ (1), S. schleiferi subsp. coagulans ATCC $49545^{\mathrm{T}}$ (2), and bovine testicular hyaluronidase (3). Panel (b) Southern analysis of ClaI-digested chromosomal DNA isolated from S. hyicus subsp. hyicus ATCC $11249^{\mathrm{T}}$ (1), S. schleiferi subsp. coagulans ATCC $49545^{\mathrm{T}}$ (2), S. aureus SH1000 (3), and Sanger-252 (4). M: marker (kilobases).

The hyaluronidase-producing strains of S. aureus examined included three ATCC strains, eight sequenced strains, and two isolates of pulse-field type, USA-300 (Miss and LAC) (Table 1). The remaining strains examined included 17 vaginal toxic shock syndrome- (TSS-) producing clinical isolates and 15 clinical strains (Table 1). The identity of the three hyaluronidase nonproducing strains as $S$. aureus (NCH 241, 242, and 250) was determined by Gram stain, growth on mannitol salt agar and catalase, coagulase, and DNAse activities (data not shown). Their identities were confirmed using the Vitek 2 Compact (bioMérieux, Durham, N.C.) automated system and the ID-GP identification cards (bioMérieux). Strain NCH 242 was identified as S. aureus with low discrimination between it and $S$. intermedius but was positive with the Voges-Proskauer test. Staphylococcus intermedius, like $S$. aureus, produces coagulase and DNAse as well as utilize mannitol [13]. However, unlike S. aureus,
S. intermedius is unable to ferment glucose to acetylmethylcarbinol (acetoin), and thus, is negative with the VogesProskauer test [13].

3.2. Southern Analysis. Chromosomal DNA was isolated from all strains and digested with the restriction endonuclease, ClaI. This enzyme was chosen because it does not cut within the open reading frame of any of the hyaluronidase genes found in the 14 sequenced $S$. aureus genomic databases (data not shown). Digested DNA resolved by gel electrophoresis was analyzed by Southern analysis using a probe generated from the sequence of one of the hyaluronidase genes (hysA1) found in S. aureus UAMS-1 and from the corresponding gene found in S. aureus RN6390. Under high stringency conditions $\left(65^{\circ} \mathrm{C}\right.$ and low salt) both probes hybridized to the same ClaI fragment containing a hyaluronidase gene with equal intensities (data not shown). Staphylococcus aureus SH1000 (8325 lineage) and Sanger252 were included in all Southern analysis as representative strains containing one and two hys $A$ genes, respectively, as demonstrated by sequence analysis of their respective databases and independent cloning and sequencing of all three genes (data not shown).

Approximately half (53.5\%) of the 43 S. aureus strains examined exhibited two hybridizing bands and two strains (NTH 79 and 81) exhibited three hybridizing bands (Table 1 and Figures 1 and 2). These data suggest that these strains contain multiple copies of the hyaluronidase gene. The existence of smaller ClaI hybridizing fragments was noted for two strains, NTH 75 and NTH 78, and so the potential for restriction fragment length polymorphism exists. None of the remaining 19 species of Staphylococcus exhibited a hybridizing band for hys A (Figures 1 and 2) including the type strain for $S$. hyicus subsp. hyicus ATCC $11249^{\mathrm{T}}$ (Figure 3(b)).

\subsection{Detecting Hyaluronidase-Producing Strains on TSHA.} Three strains of Staphylococcus, S. aureus strain ATCC 33753, S. aureus strain Newman, and S. epidermidis strain ATCC 12228 exhibiting a large $(13.2 \pm 1.3)$, small $(5.8 \pm 2.5)$, and no zone of activity on HA plates, respectively, were mixed and plated onto TSHA to determine whether or not TSHA could be used to discern Staphylococcus strains expressing hyaluronidase at different levels. All three strains could easily be discerned, as evident by the differences in zone sizes after overnight incubation at $37^{\circ} \mathrm{C}$ (Figure 4 ).

\section{Discussion}

Previous studies $[23,24]$ examined a large number of staphylococcal strains for the presence of hyaluronidase activity. While species identity was not determined in most cases, the strains were characterized as either positive or negative for coagulase or DNAse activities, characteristics typically used to distinguish $S$. aureus from other staphylococcal species [13]. In these studies $[23,24]$ the vast majority $(93 \%)$ of strains that exhibited coagulase and DNAse activities also exhibited hyaluronidase activity. 


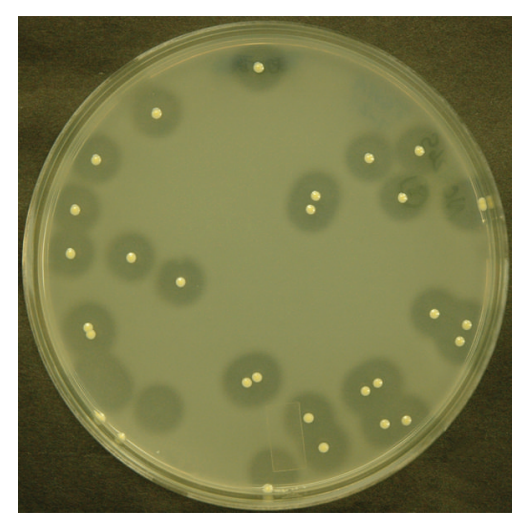

(a)

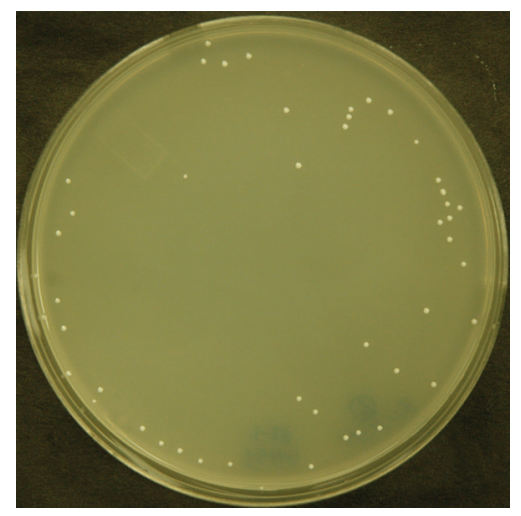

(c)

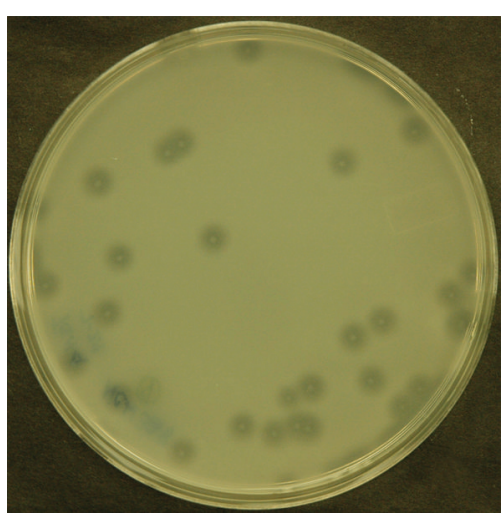

(b)

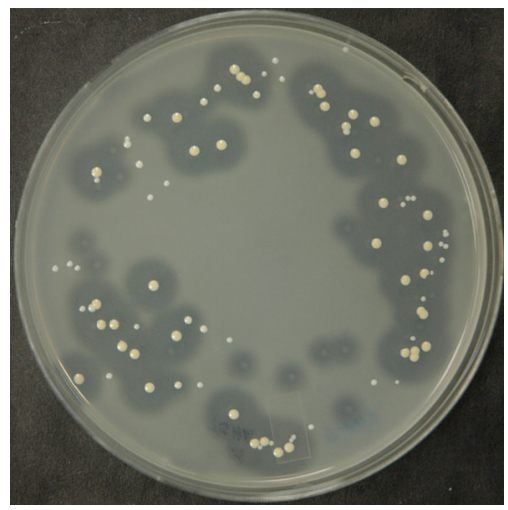

(d)

Figure 4: Hyaluronidase detection on tryptic soy agar supplemented with hyaluronic acid. S. aureus ATCC 33753 (a), S. aureus Newman (b), S. epidermidis ATCC 12228 (c), and a mixture of all three (d). Colonies of S. aureus Newman did not adhere to the agar surface when acetic acid was removed from the plates for photographic documentation.

In the present study, we have examined the type strain for 20 different species of Staphylococcus for their ability to degrade hyaluronic acid and of these, only $S$. aureus strains exhibited hyaluronidase activity. In addition, over half of the $S$. aureus strains examined exhibited two or more genes for hyaluronidase. While the number of genes per strain will need to be confirmed, we know from the genomic databases of $S$. aureus Sanger-252 and RF-122 [11, 28,29 ] and the proteomic analysis of S. aureus UAMS-1 [10] that these strains contain two genes for hyaluronidase. Whether or not the presence of two or more hyaluronidase genes affords some metabolic or pathogenic advantage is currently under investigation. However, it must be pointed out that an increase in the number of potential genes for any one strain did not necessarily result in an increase in hyaluronidase activity as determined with the hyaluronidase assay used in this study. In addition, not all $S$. aureus strains produced hyaluronidase although Southern analysis indicated the presence of at least one gene in each of the three strains that failed to exhibit hyaluronidase activity. It is also interesting that two of these hyaluronidase nonproducing strains appear to have two hysA genes. While at present we have no supporting data, this might suggest that either these strains carry two copies of the same defective gene or an important regulator of $h y s A$ expression is nonfunctional. Nevertheless, given the limited number of $S$. aureus strains examined in our study and the fact that some strains did not produce hyaluronidase would suggest that the lack of hyaluronidase by $S$. aureus is more prevalent than originally thought and that the enzyme may not be a contributing factor in virulence. Whether this is true or not will require further investigation particularly given that hyaluronidase has been implicated as a virulence factor in the mouse abscess model [9] and that the primarily virulence gene regulator, SarA, controls its expression [9, $10]$.

We are also intrigued that under our assay conditions as well as the Southern analysis that S. hyicus subsp. hyicus, a strain known to cause infectious exudative epidermititis in swine and reported to have hyaluronidase activity $[13,19$, 25], exhibited no activity nor did it have a hybridizing band corresponding to the hysA gene from S. aureus. Currently, it is unclear as to why this discrepancy exists other than previous investigations $[13,19,25]$ relied on the appearance of nonmucoid colonies of Streptococcus equi, which possesses a hyaluronic acid-containing capsule $[30,31]$ on blood agar when Streptococcus equi was plated as a lawn and Staphylococcus species, including $S$. hyicus were "spot" inoculated 
onto the lawn [32]. This would suggest, perhaps, that some factor other than hyaluronidase contributes to the formation of nonmucoid Streptococcus equi colonies.

Lastly, while the method employed in this study clearly distinguished hyaluronidase-producing colonies from those that did not, more than likely the detection of hyaluronidase activity as a diagnostic test for the presumptive identification of $S$. aureus would not be feasible given the fact that not all $S$. aureus strains possess hyaluronidase activity. However, using methods that detect the presence or absence of the gene could possibly be used as $100 \%$ of the S. aureus strains examined in this study contained at least one gene for hysA.

\section{Acknowledgments}

This research was supported by protocol E0717501 awarded to M. E. Hart by the National Center for Toxicological Research (NCTR) of the United States Food and Drug Administration. Support for undergraduates M. J. Hart and A. J. Roop was provided by the Student Research Participation Program at NCTR and administered by the Oak Ridge Institute for Science and Education through an interagency agreement between the U.S. Department of Energy and the U.S. Food and Drug Administration and by the Division of Microbiology at NCTR. M. J. Hart and A. J. Roop contributed equally to this work. The authors are grateful to Don Paine and Roger Steele for identification of strains. They are also indebted to Drs. Carl Cerniglia, Chris Elkins, and John Sutherland for careful evaluation of the manuscript. The views presented in this article do not necessarily reflect those of the United States Food and Drug Administration.

\section{References}

[1] Q. Cheng, M. C. Yu, A. R. Reeves, and A. A. Salyers, "Identification and characterization of a Bacteroides gene, csuF, which encodes an outer membrane protein that is essential for growth on chondroitin sulfate," Journal of Bacteriology, vol. 177, no. 13, pp. 3721-3727, 1995.

[2] K. Homer, H. Shain, and D. Beighton, "The role of hyaluronidase in growth of Streptococcus intermedius on hyaluronate," Advances in Experimental Medicine and Biology, vol. 418, pp. 681-683, 1997.

[3] W. L. Hynes and S. L. Walton, "Hyaluronidases of grampositive bacteria," FEMS Microbiological Letters, vol. 183, no. 2, pp. 201-207, 2000.

[4] J. I. Rood and S. T. Cole, "Molecular genetics and pathogenesis of Clostridium perfringens," Microbiological Reviews, vol. 55, no. 4, pp. 621-648, 1991.

[5] H. Shain, K. A. Homer, and D. Beighton, "Degradation and utilisation of chondroitin sulphate by Streptococcus intermedius," Journal of Medical Microbiology, vol. 44, no. 5, pp. 372-380, 1996.

[6] L. D. Smith, "Virulence factors of Clostridium perfringens," Reviews of Infectious Diseases, vol. 1, no. 2, pp. 254-262, 1979.

[7] C. R. Starr and N. C. Engleberg, "Role of hyaluronidase in subcutaneous spread and growth of group A Streptococcus," Infection and Immunity, vol. 74, no. 1, pp. 40-48, 2006.
[8] R. Stern and M. J. Jedrzejas, "Hyaluronidases: their genomics, structures, and mechanisms of action," Chemical Reviews, vol. 106, no. 3, pp. 818-839, 2006.

[9] G. Makris, J. D. Wright, E. Ingham, and K. T. Holland, "The hyaluronate lyase of Staphylococcus aureus: a virulence factor?" Microbiology, vol. 150, no. 6, pp. 2005-2013, 2004.

[10] R. C. Jones, J. Deck, R. D. Edmondson, and M. E. Hart, "Relative quantitative comparisons of the extracellular protein profiles of Staphylococcus aureus UAMS-1 and its sarA, agr, and sarA agr regulatory mutants using one-dimensional polyacrylamide gel electrophoresis and nanocapillary liquid chromatography coupled with tandem mass spectrometry," Journal of Bacteriology, vol. 190, no. 15, pp. 5265-5278, 2008.

[11] P. Kersey, L. Bower, L. Morris, et al., "Integr8 and genome reviews: integrated views of complete genomes and proteomes," Nucleic Acids Research, vol. 33, pp. D297-D302, 2005.

[12] J. P. Euzéby, "List of bacterial names with standing in nomenclature: a folder available on the Internet," International Journal of Systematic Bacteriology, vol. 47, no. 2, pp. 590-592, 1997.

[13] W. E. Kloos and K. H. Schleifer, "Staphylococcus," in Bergey's Manual of Systematic Bacteriology, P. H. A. Sneath, N. S. Mair, M. E. Sharpe, and J. G. Holt, Eds., pp. 1013-1035, The Williams and Wilkins, Baltimore, Md, USA, 1986.

[14] G. L. Archer, "Staphylococcus epidermidis and other coagulasenegative staphylococci," in Principles and Practice of Infectious Diseases, G. L. Mandell, J. E. Bennett, and R. Dolin, Eds., pp. 1777-1784, Churchill Livingstone, New York, NY, USA, 1995.

[15] D. J. Diekema, M. A. Pfaller, F. J. Schnitz, et al., "Survey of infections due to Staphylococcus species: frequency of occurrence and antimicrobial susceptibility of isolates collected in the United States, Canada, Latin America, Europe, and the western Pacific region for the SENTRY antimicrobial surveillance program, 1997-1999," Clinical Infectious Diseases, vol. 32, no. 10, supplement 2, pp. S114-S132, 2001.

[16] J. Huebner and D. A. Goldmann, "Coagulase-negative staphylococci: role as pathogens," Annual Review of Medicine, vol. 50, pp. 223-236, 1999.

[17] W. E. Kloos and T. L. Bannerman, "Update on clinical significance of coagulase-negative staphylococci," Clinical Microbiology Reviews, vol. 7, no. 1, pp. 117-140, 1994.

[18] W. E. Kloos and T. L. Bannermann, "Staphylococcus and Micrococcus," in Manual of Clinical Microbiology, P. R. Murray, E. J. Baron, M. A. Pfaller, F. C. Tenover, and R. H. Yolken, Eds., pp. 289-298, ASM Press, Washington, DC, USA, 1995.

[19] L. A. Devriese, V. Hájek, P. Oeding, et al., "Staphylococcus hyicus (Sompolinsky 1953) comb. nov. and Staphylococcus hyicus subsp. chromogenes subsp. nov.," International Journal of Systematic Bacteriology, vol. 28, no. 4, pp. 482-490, 1978.

[20] G. Foster, H. M. Ross, R. A. Hutson, and M. D. Collins, "Staphylococcus lutrae sp. nov., a new coagulase-positive species isolated from otters," International Journal of Systematic Bacteriology, vol. 47, no. 3, pp. 724-726, 1997.

[21] M. M. Martin de Nicolás, A. Vindel, and J. A. Sáez-Nieto, "Epidemiological typing of clinically significant strains of coagulase-negative staphylococci," Journal of Hospital Infection, vol. 29, no. 1, pp. 35-43, 1995.

[22] P. E. Varaldo, R. Kilpper-Bälz, F. Biavasco, G. Satta, and K. H. Schleifer, "Staphylococcus delphini sp. nov., a coagulasepositive species isolated from dolphins," International Journal of Systematic Bacteriology, vol. 38, no. 4, pp. 436-439, 1988.

[23] K. K. Choudhuri and A. N. Chakrabarty, "Hyaluronate lyase activity of staphylococci," Indian Journal of Experimental Biology, vol. 7, no. 3, pp. 183-185, 1969. 
[24] L. Essers and K. Radebold, "Rapid and reliable identification of Staphylococcus aureus by a latex agglutination test," Journal of Clinical Microbiology, vol. 12, no. 5, pp. 641-643, 1980.

[25] K. Saito, T. Higuchi, A. Kurata, T. Fukuyasu, and K. Ashida, "Characterization of non-pigmented Staphylococcus chromogenes," Journal of Veterinary Medical Science, vol. 58, no. 7, pp. 711-713, 1996.

[26] M. Kuroda, T. Ohta, I. Uchiyama, et al., "Whole genome sequencing of meticillin-resistant Staphylococcus aureus," The Lancet, vol. 357, no. 9264, pp. 1225-1240, 2001.

[27] B. Steiner and D. Cruce, "A zymographic assay for detection of hyaluronidase activity on polyacrylamide gels and its application to enzymatic activity found in bacteria," Analytical Biochemistry, vol. 200, no. 2, pp. 405-410, 1992.

[28] L. Herron-Olson, J. R. Fitzgerald, J. M. Musser, and V. Kapur, "Molecular correlates of host specialization in Staphylococcus aureus," PLoS ONE, vol. 2, no. 10, article e1120, 2007.

[29] M. T. G. Holden, E. J. Feil, J. A. Lindsay, et al., "Complete genomes of two clinical Staphylococcus aureus strains: evidence for the evolution of virulence and drug resistance," Proceedings of the National Academy of Sciences of the United States of America, vol. 101, no. 26, pp. 9786-9791, 2004.

[30] L. M. Blank, P. Hugenholtz, and L. K. Nielsen, "Evolution of the hyaluronic acid synthesis (has) operon in Streptococcus zooepidemicus and other pathogenic streptococci," Journal of Molecular Evolution, vol. 67, no. 1, pp. 13-22, 2008.

[31] D. J. Harrington, I. C. Sutcliffe, and N. Chanter, "The molecular basis of Streptococcus equi infection and disease," Microbes and Infection, vol. 4, no. 4, pp. 501-510, 2002.

[32] L. A. Devriese and P. Oeding, "Coagulase and heat resistant nuclease producing Staphylococcus epidermidis strains from animals," Journal of Applied Bacteriology, vol. 39, no. 2, pp. 197-207, 1975. 

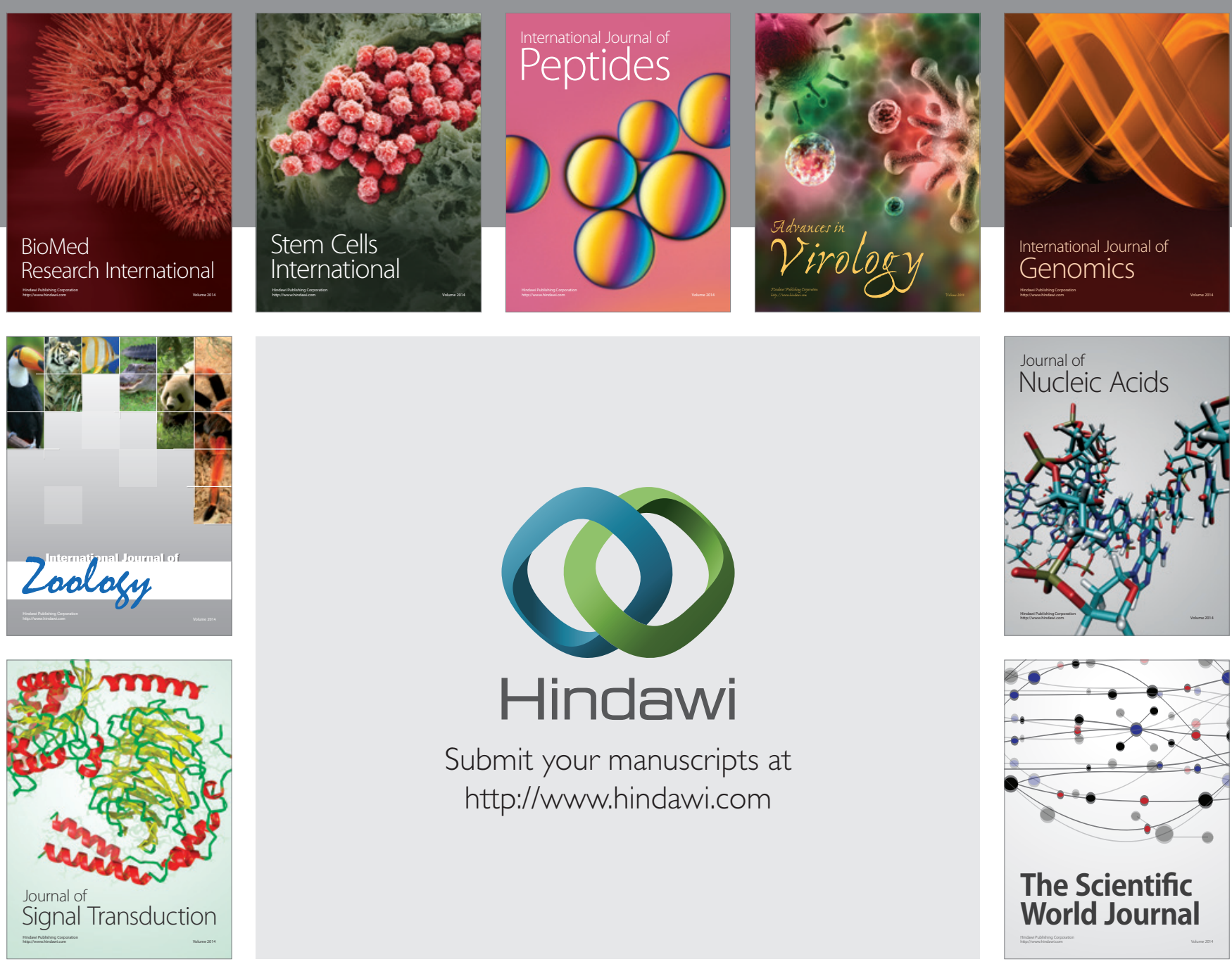

Submit your manuscripts at

http://www.hindawi.com
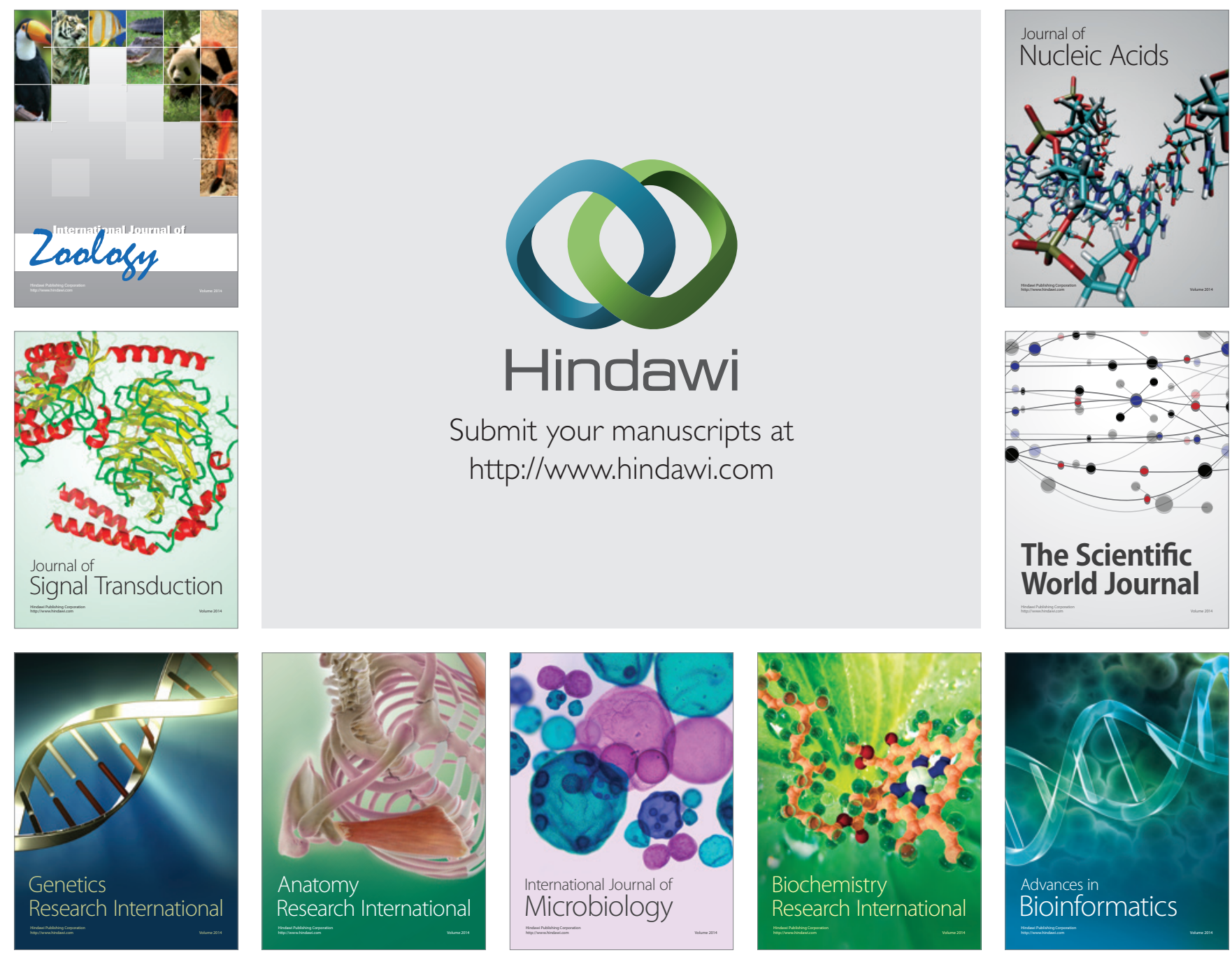

The Scientific World Journal
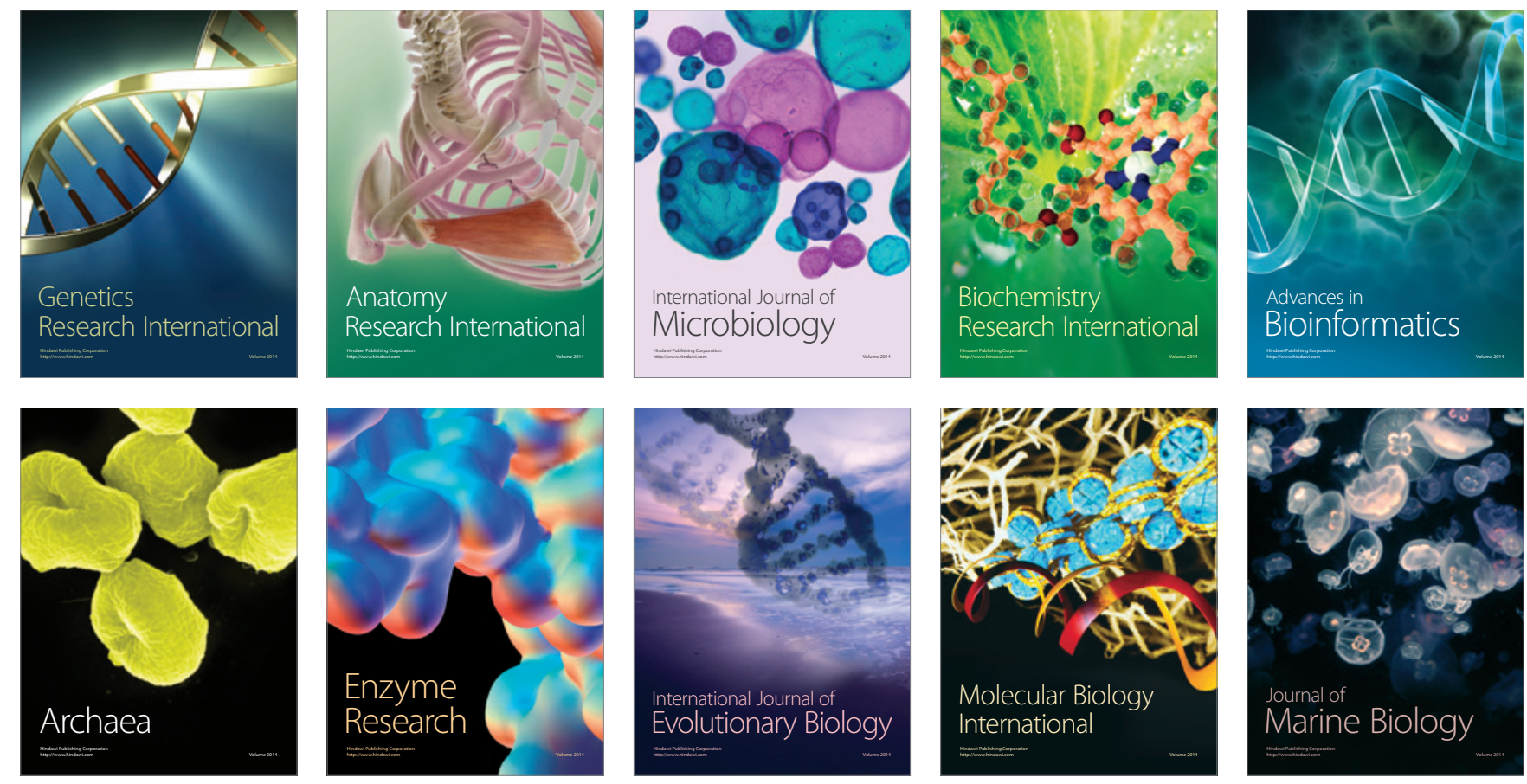